(RESEARCH ARTICLE)

\title{
Reproductive toxicity of iron oxide nanoparticles, silver nanoparticles and their mixture in male rats: Effects on testicular gene expression
}

\author{
Ahmed Ibrahim Younus 1, *, Mokhtar Ibrahim Yousef2, Kamel Maher Abdel-Nabi ${ }^{3}$, Mohammed Ibrahim \\ Younus ${ }^{4}$ and Jubran Mohammed Abdulrahman ${ }^{5}$ \\ ${ }^{1}$ Ministry of Health, Iraq. \\ ${ }^{2}$ Department of Environmental Studies, Institute of Graduate Studies and Research, Alexandria University, Egypt. \\ ${ }^{3}$ Department of Biochemistry, Medical Research Institute, Alexandria University, Egypt. \\ ${ }^{4}$ College of Medicine, University of Anbar, Ministry of Higher Education and Scientific Research, Iraq. \\ ${ }^{5}$ Center of Research and Educational Studies, Ministry of Education, Iraq.
}

Publication history: Received on 25 July 2020; revised on 08 August 2020; accepted on 10 August 2020

Article DOI: https://doi.org/10.30574/wjarr.2020.7.2.0278

\begin{abstract}
Iron oxide nanoparticles ( $\mathrm{Fe}_{2} \mathrm{O}_{3} \mathrm{NPs}$ ) have shown wide biological applications in magnetic resonance imaging (MRI), drug delivery, gene therapy, cancer treatments, in vitro diagnostics (IVD), and vaccine and antibody production. Although $\mathrm{Fe}_{2} \mathrm{O}_{3} \mathrm{NPs}$ have a variety of applications, few studies have demonstrated that exposure to $\mathrm{Fe}_{2} \mathrm{O}_{3} \mathrm{NPs}_{\mathrm{may}}$ lead to adverse effects, such as reproductive toxicity. Silver nanoparticles (AgNPs) are widely used in products across industries; they are often used for their antimicrobial activity in medicine and are also often found in detergents. Few studies have demonstrated that exposure to AgNPs may lead to adverse effects, such as reproductive toxicity. There is no enough results on the reproductive toxicity induced by $\mathrm{Fe}_{2} \mathrm{O}_{3} \mathrm{NPs}$ and AgNPs, especially in combination. Therefore, the present study aimed to investigate the reproductive toxicity of iron oxide nanoparticles, silver nanoparticles and their combination in male rats. In the present study Wistar male rats were used. Animals were divided into 4 equal groups, 10 rats each. Group 1 served as control, group 2 was administered orally with $\mathrm{Fe}_{2} \mathrm{O}_{3} \mathrm{NPs}(5 \mathrm{mg} / \mathrm{kg} \mathrm{BW} ;<50 \mathrm{~nm})$, group 3 was treated intraperitoneally with AgNPs $(50 \mathrm{mg} / \mathrm{kg} \mathrm{BW} ;<100 \mathrm{~nm}$ ) and group 4 was administered with the mixture of $\mathrm{Fe}_{2} \mathrm{O}_{3} \mathrm{NPs}$ with AgNPs. Animals were treated with doses every day for 79 days. Treatment with $\mathrm{Fe}_{2} \mathrm{O}_{3} \mathrm{NPs}$, AgNPs and their combination caused significant $(\mathrm{P}<0.05)$ changed in gene expression of mitochondrial transcription factor-A (mtTFA) and uncoupling protein 2 (UCP 2) in testes compared to control group.
\end{abstract}

Keywords: Iron oxide nanoparticles; Silver nanoparticles; Male rats; Gene expression

\section{Introduction}

In recent years, reproductive and developmental toxicity has increasingly become recognized as an important part of overall toxicology. In fact, adverse effects of environmental chemicals on the reproductive success of wildlife populations have been noted [1]. It is reported that nanoparticles can pass through biological Membranes raising fears that they can affect the physiology of any cell in the body. The possibility of chemicals entering biological systems is of great concern to the public with regard to possible reproductive and developmental toxicity [2, 3]. Mitochondria contain their own genome. Mitochondrial DNA (mtDNA) is located in the mitochondrial matrix and is present in multiple copies per mitochondrion (4). It consists of a light strand, a heavy strand (rich in guanine) and a small fragment called the displacement loop or D-loop. mtDNA does not contain introns and both strands of circular mtDNA are transcribed as long primary transcripts corresponding to several genes. These primary transcripts are processed to release the individual tRNA, rRNA and mRNA [5]. The mitochondrial function and biogenesis is under the control of nuclear encoded proteins; mainly mitochondrial transcription factor A (mtTFA) and uncoupling proteins (UCPs) [6, 7]. Mitochondrial transcription factor A (mtTFA) gene is a single copy nuclear gene which encodes for an activator of 
mitochondrial transcription in mammals. The gene encoding mtTFA is located on the chromosome 10 at the locus 10q21.1. mtTFA gene in mammals is estimated to span about $10 \mathrm{~kb}$ and is structured in seven exons and six introns in rat, mouse and human [8]. mtTFA is widely distributed in mammalian tissues as well as highly conserved, short (741 base pair) and guanine cytosine (GC) poor. The gene expression of mtTFA is altered depending on the cellular conditions and directly regulated by several transcription factors such as nuclear respiratory factor (NRF)-1 and NRF-2. The fulllength cDNA of this nuclear gene encodes 246 amino acids of mtTFA (precursor form). The N-terminal 42 amino acids function as mitochondrial targeting signal and are cleaved during mitochondrial translocation. Thus, the mature mtTFA functional form is composed of 204 amino acids $(25 \mathrm{kDa}$ ) [9]. "The mtTFA protein not only plays an important role in the maintenance of mtDNA integrity but also in mtDNA replication and transcription [10]. The Mitochondrial transcription factor A (mtTFA) binds mtDNA with an affinity compatible with the idea of the protein coating the genome, shows a strong preference for DNA with protein already bound, and is sufficient to compact and assemble DNAs into multigenomic nucleoid-like structures [11]. Transcription of mtDNA occurs following interaction between nuclearencoded regulatory proteins and regions within the D-loop of mtDNA [6]. "Requirements for transcription include the mitochondrial RNA polymerase, mitochondrial transcription factor A and one of the recently identified TFB1M and TFB2M [8]. Once initiated, transcription generates a polycistronic precursor RNA transcript, allowing coordinated transcription of all genes on the same strand. Excision of the polycistronic precursor by endonucleases produces precursor rRNAs and tRNAs, which are then processed further to allow them to translate the precursor mRNAs [5]. Uncoupling proteins (UCPs) are other nuclear encoded proteins that play a pivotal role in controlling mitochondrial functions. Mitochondrial uncoupling refers to the dissociation of electron-dependent oxygen consumption to ATP generation on the respiratory chain. The most efficient way to induce mitochondrial uncoupling is to allow protons to circulate freely across the inner mitochondrial membrane, in other words to create a proton leak [12]. In this regard, the UCPs are a professional mitochondrial uncoupler dissipating the proton gradient by allowing the re-entry of protons into the mitochondrial matrix during oxidative ATP generation, resulting in the uncoupling of the respiratory chain and heat production [13]. UCPs are a family of mitochondrial transport proteins located in the inner mitochondrial membrane. Here are five UCPs (named UCP 1 to 5) found in mammals. These anion-carrier proteins transport protons $\left(\mathrm{H}^{+}\right)$to the mitochondrial matrix and in turn dissipate the proton motive force as heat and uncouple the substrate oxidation from the production of ATP. These proteins have similarities in their structures, but different tissue distributions in mammals [14]. The UCPs are integral membrane proteins, each with a molecular mass of 31-34 kDa and a tripartite structure in which a region of around 100 residues is repeated three times; each repeat codes for two transmembrane segments and a long hydrophilic loop. The functional carrier unit is a homodimer [15]. In 1997, Fleury et al. [16] cloned and sequenced a gene homologous to Uncoupling proteins 1 (UCP1) gene, later called Uncoupling proteins 2 (UCP2). UCP2 gene covers a $6.3 \mathrm{~kb}$ region on chromosome 11 (region 11q13), and has eight exons and seven introns [16]. In humans, region 11q13 is linked to basal metabolic rate and body fat percentage. The transcriptional gene unit is constituted by two non-coding exons followed by six exons that encode the 308 amino acids of the protein. Human UCP2 share $57 \%$ amino acidsequence identity with human UCP1, and it is $71 \%$ identical to human Uncoupling proteins 2 (UCP3). In addition, the amino acid sequence of human UCP2 is 95\% identical to mouse UCP2 [17]. An accumulating set of data, suggested that the new UCPs should be considered as mitochondrial carriers beside uncoupling proteins. The genetic loss of Uncoupling proteins 2 (UCP2) leads to a faster proliferative rate associated with decreased mitochondrial fatty acid oxidation and increased glucose metabolism. The idea that UCP2 acts as a regulator of mitochondrial fatty acid oxidation is consistent with previous studies suggesting that UCP2 plays a role in lipid metabolism by promoting a shift from carbohydrate to lipid metabolism during fasting or by transporting free fatty acids out of mitochondria [18]. Parton et al, have shown that UCP2 negatively regulates glucose sensing in neurons and its absence prevents obesity-induced loss of glucose sensing [7].

The objective of this study was to investigate the effects of iron oxide nanoparticles, silver nanoparticles and their mixture on testicular gene expression of genes regulating mitochondrial biogenesis and function; mitochondrial transcription factor-A and uncoupling protein 2 in male rats.

\section{Material and methods}

\subsection{Materials}

Iron oxide nanoparticles $\left(\mathrm{Fe}_{2} \mathrm{O}_{3} \mathrm{NPs}\right.$ ), Nano powder $<50 \mathrm{~nm}$ particle size (TEM) and Silver nanoparticles (AgNPs), Nano powder $<100 \mathrm{~nm}$ particle size were purchased from Sigma-Aldrich Chemical Company, (St Louis, MO, USA). Iron oxide nanoparticles was dissolved in distilled water and orally treated at a dose of $5 \mathrm{mg} / \mathrm{kg} \mathrm{BW}$ [19]. Silver nanoparticles was dissolved in distilled water and intraperitoneally injected at a dose of $50 \mathrm{mg} / \mathrm{kg} / \mathrm{day}$ according to Sharma et al. [20]. 


\subsection{Animals}

Forty adult male Wistar rats weighing 160-170 g and 5-6 months of age of were used in the present study. Animals were obtained from Faculty of Medicine, Alexandria University, Alexandria, Egypt. Animals were kept on basal diet and tap water which were provided ad libitum. Rats were fed pellets consisted of $30 \%$ berseem (Trifolium alexandrinum) hay, $25 \%$ yellow corn, $26.2 \%$ wheat bran, $14 \%$ whole soybean meal, $3 \%$ molasses, $1 \% \mathrm{CaCl} 2,0.4 \% \mathrm{NaCl}, 0.3 \%$ mixture of minerals and vitamins $(0.01 \mathrm{~g} / \mathrm{kg}$ diet of Vitamin $\mathrm{E})$ and $0.1 \%$ methionine. The vitamin and mineral premix per kilogram contained the following vitamins: A, 4,000,000 IU;D3, 5000,000 IU; E, $16.7 \mathrm{~g} ; \mathrm{K}, 0.67 \mathrm{~g} ; \mathrm{B} 1,0.67 \mathrm{~g} ; \mathrm{B} 2,2 \mathrm{~g} ; \mathrm{B} 6,0.67 \mathrm{~g} ; \mathrm{B} 12$, $0.004 \mathrm{~g}$; B5, $16.7 \mathrm{~g}$; pantothinc acid, $6.67 \mathrm{~g}$; biotein, $0.07 \mathrm{~g}$; folic acid, $1.67 \mathrm{~g}$; choline chloride, $400 \mathrm{~g}$; minerals: Zn, 23.3 g; Mn, 10 g; Fe, 25 g; Cu, 1.67 g; I, 0.25 g; Se, 0.033 g; Mg, 133.4 g (rabbit premix produced by Holland Feed Int. Co.). The chemical analysis of the pellets [21] showed that they contained $17.5 \%$ crude protein, $14.0 \%$ crude fiber, $2.7 \%$ crude fat and $2200 \mathrm{kcal}$ digest able energy/kg diet. After two weeks of acclimation, animals were divided into 4 equal groups, 10 rats each. Group 1 served as control, group 2 was administered orally with $\mathrm{Fe}_{2} \mathrm{O}_{3} \mathrm{NPs}$ ( $5 \mathrm{mg} / \mathrm{kg} \mathrm{BW} ;<50 \mathrm{~nm}$ ), group 3 was treated interpersonal with AgNPs $(50 \mathrm{mg} / \mathrm{kg} \mathrm{BW} ;<100 \mathrm{~nm})$ and group 4 was administered with the mixture of $\mathrm{Fe}_{2} \mathrm{O}_{3} \mathrm{NPs}$ with AgNPs. The doses of iron oxide nanoparticles and silver nanoparticles were treated every day for 79 days. Rats were observed carefully during the acclimatization and experimental periods to monitor any animal showing signs of toxicity, stress, physical damage or mortality.At the end of the $79^{\text {th }}$ day of the experimental period, all animals of each group were anaesthetized with diethyl ether and sacrificed. This work was approved by the ethical committee at the Institute of Graduate Studies and Research, Alexandria University, Egypt.

\subsection{Sample collection}

Blood samples were collected from anaesthetized rats in test tubes containing heparin as an anticoagulant and placed immediately on ice. The blood samples were centrifuged at $860 \mathrm{Xg}$ for $20 \mathrm{~min}$ for the separation of plasma. The plasma was kept at $-80^{\circ} \mathrm{C}$ until analyses of the tested parameters. Testes were immediately removed, washed using chilled saline solution $(0.9 \%)$, and removed the adhering fat and connective tissues. Testes were minced and homogenized $(10 \%, w / v)$, separately, in ice-cold sucrose buffer $(0.25 \mathrm{M})$ in a Potter-Elvehjem type homogenizer. The homogenates were centrifuged at $10,000 \mathrm{Xg}$ for $20 \mathrm{~min}$ at $4{ }^{\circ} \mathrm{C}$, to pellet the cell debris and the supernatant was harvested and stored at $-80^{\circ} \mathrm{C}$ for the determination of tested parameters. The epididymis was removed and cleaned from fat adhesive tissue, washed in cold physiological saline repeatedly and kept in physiological solution for spermatological analysis by using a computer assisted semen analyzer (CASA). Pieces of both right and left testes were kept in formalin $10 \%$ for histopathological studies.

\subsection{Molecular assay}

Total RNA was isolated from testicular tissues using GF-1. Total RNA Extraction Kit (Vivantis, Malaysia) according to the manufacturer instructions. The GF-1 Total RNA Extraction Kitis designed for the isolation of total RNA (longer than 200 bases) from animal tissues. Samples are lysed in the presence of a specially formulated buffer which inactivates cellular RNases. Meanwhile, fragments of DNA are simply removed by applying the sample into a specially designed homogenization column followed by DNasel treatment. Optimized buffer and ethanol are added to provide selective binding of RNA onto the column matrix while contaminants are efficiently washed away. High-quality RNA is then eluted in RNase-free water [22].

\subsection{Statistical analysis}

Results are reported as means \pm SE. Statistical analysis for all studied parameters were performed using the general linear model (GLM) produced by Statistical Analysis Systems Institute. Duncan's New Multiple Range Test was used to test the significance of the differences between means [23]. Values of $\mathrm{p}<0.05$ were considered statistically significant..

\section{Results and discussion}

Table 1 and Figures 1 summarize the results of the quantitative real time RT-PCR gene expression analysis of mtTFA and UCP2 in the testicular tissues obtained from control rats and rats treated with nanparticles. The results showed suppression of the testicular gene expression of mtTFA in the rats treated with iron oxide nanoparticles $\left(\mathrm{Fe}_{2} \mathrm{O}_{3} \mathrm{NPs}\right)$ to be about one third its levels in the control rats, while silver nanoparticles (AgNPs) treatment significantly suppress the expression of mtTFA by about the half. The treatment with the combination of iron oxide and silver NPs results in significant suppression of the expression of mtTFA to the extent similar to that observed with the iron oxide nanoparticles treatment. 
Table 1 The effect of iron oxide nanoparticles (Fe203NPs), Silver nanoparticles (AgNPs) and their combination treatments on the testicular gene expression of genes regulating mitochondrial biogenesis and function; mitochondrial transcription factor-A (mtTFA) and uncoupling protein 2 (UCP2).

\begin{tabular}{lllll}
\hline \multirow{2}{*}{ Parameter } & \multicolumn{4}{l}{ Experimental groups } \\
\cline { 2 - 5 } & Control & Fe203 & Ag & Fe203 + Ag \\
\hline mtTFA (Fold control) & $1 \pm 0.05 \mathrm{a}$ & $0.37 \pm 0.06 \mathrm{c}$ & $0.52 \pm 0.02 \mathrm{~b}$ & $0.35 \pm 0.04 \mathrm{c}$ \\
UCP2 (Fold control) & $1 \pm 0.06 \mathrm{~d}$ & $4.07 \pm 0.31 \mathrm{~b}$ & $1.93 \pm 0.11 \mathrm{c}$ & $5.2 \pm 0.47 \mathrm{a}$ \\
\hline
\end{tabular}

Mean values within a row not sharing a common superscript letters $(a, b, c)$ were significantly different, $p<0.05$. mtTFA =Mitochondrial transcription factor-A, UCP2= Uncoupling protein 2.
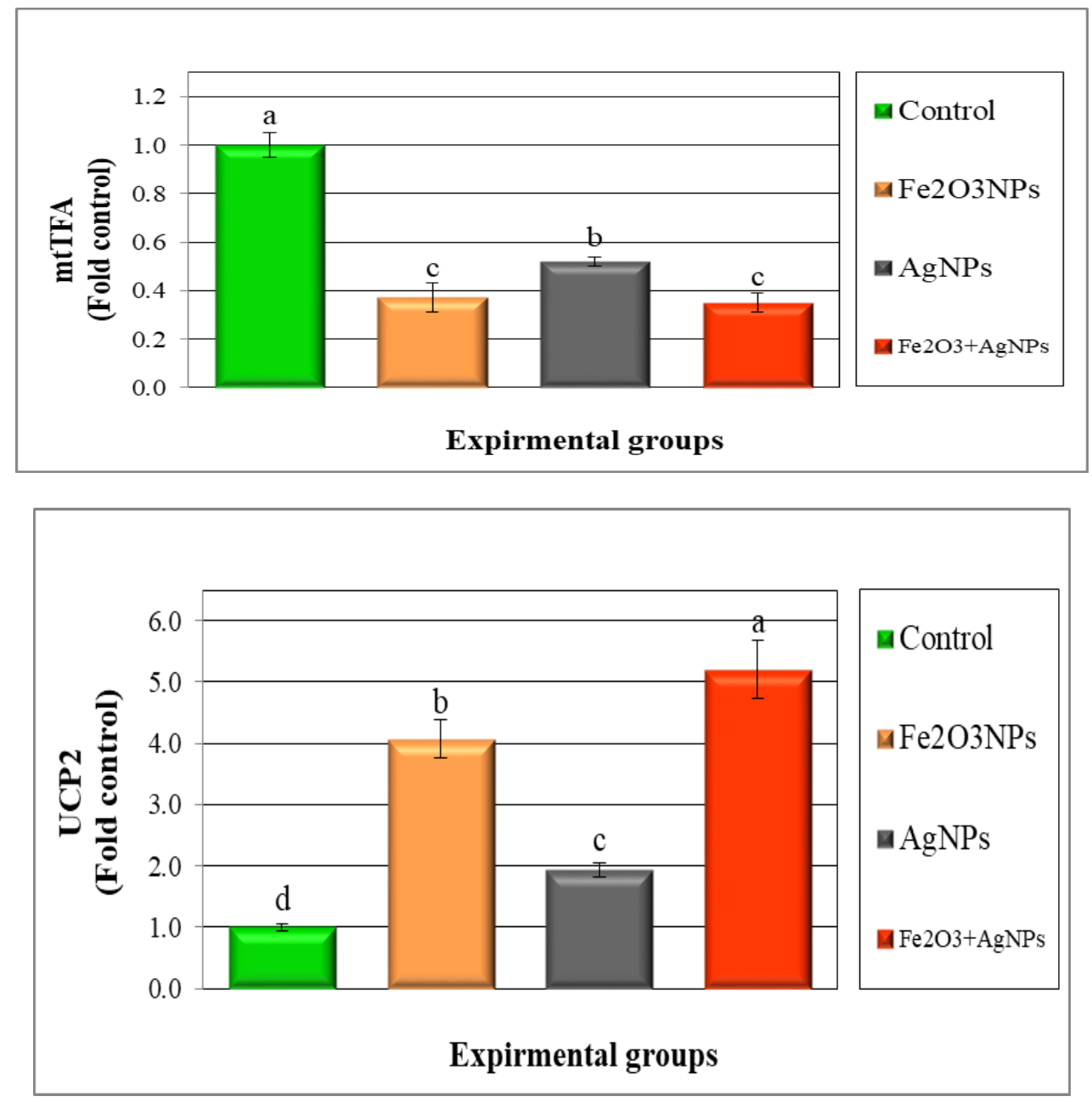

Figure 1The effect of iron oxide nanoparticles (Fe203NPs), Silver nanoparticles (AgNPs) and their combination treatments on the testicular gene expression of genes regulating mitochondrial biogenesis and function; mitochondrial transcription factor-A (mtTFA) and uncoupling protein 2 (UCP2).

On the other hand, the testicular gene expression of UCP2 showed significant induction in the rats treated with each one of the two NPs (iron oxide and silver NPs). The iron oxide nanoparticles showed great induction of the UCP2 expression by about 4-fold the control level while silver nanoparticles treatment results in about 2 -fold increase. The treatment with the combination of iron oxide nanoparticles and silver nanoparticles showed the highest induction (more than 5folds the control value). Mitochondria are the eukaryotic cell's powerhouses, for they generate roughly $90 \%$ of the energy the cells utilizes, in the form of ATP [24].The generation of ATP is one of the dozens of key roles mitochondria play in maintaining cell viability. As such, it comes as no surprise that the disruption of mitochondrial homeostasis is a key event in a wide variety of diseases and toxicological effects, and in even normal events such as aging [25]. Sperm mitochondria generate energy for sperm flagellar motility through oxidative phosphorylation [26]. Normal mitochondrial function is also required for earlier stages of mammalian spermatogenesis [27]. Abnormal function of 
the sperm mitochondria during spermatogenesis has been associated with infertility.The mitochondrial genome operates in a semi-autonomous manner as it is co-regulated by nuclear transcription factors. Mitochondrial transcription factor A (mtTFA) is a key transcription factor. During spermatogenesis in the mouse, mtTFA is expressed up to the late spermatocyte and early spermatid stage [28]. Mitochondrial transcription factor A, as a transcription factor is a multi-functional protein plays an important role in the maintenance of mitochondrial DNA (mtDNA) integrity, replication and transcription [10].

It has been suggested that irregularities in mitochondrial function may result in male infertility possibly due to mitochondrial respiration defects [27]. In the present study, the decreased expression of mtTFA in testicular tissues of rats treated with iron oxide nanoparticles and silver nanoparticles may indicate a decreased mitochondrial biogenesis and mtDNA replication and transcription that may lead to mitochondrial dysfunction. In line with this assumption, Teodoro et al. [29] recently documented that, sub chronic AgNPs exposure upon hepatic, renal and cardiac mitochondria. This exposure caused impairment of rat liver mitochondrial function, mainly due to alterations of mitochondrial membrane permeability. The enhancement of $\mathrm{H}^{+}$leak resulted in an uncoupling effect of the oxidative phosphorylation system which are in agreement with the present results that demonstrated an enhanced expression of the uncoupling protein 2 (UCP2).The mechanism by which nanoparticles induce the gene expression of UCP2 is unclear however we can postulate that it may a direct consequence of oxidative stress and increased free radicals and lipid peroxide which confirmed in this study. It was proposed that higher levels of superoxide or superoxide-derived lipid peroxidation products are UCP2 activators and, therefore, induce proton leak that would decrease ROS production [30].

\section{Conclusion}

It was concluded that the result of this study provided insight into the important crosstalk between the gene expression of nuclear transcription factors involved in mitochondrial biogenesis and function (namely; mtTFA and UCP2) and the reproductive toxicity of iron oxide and silver nanoparticles.

\section{Compliance with ethical standards}

\section{Acknowledgments}

The authors would like to thank the dean of Institute of Graduate Studies and Research and all administrative and teaching staffs at the institute for providing me all the facilities required for this study.

\section{Disclosure of conflict of interest}

The authors declare that they have no competing interests.

\section{Statement of ethical approval}

This work was approved by the ethical committee at the Institute of Graduate Studies and Research, Alexandria University, Egypt.

\section{References}

[1] Colborn T, VomSaal FS and Soto AM.(1993). Developmental effects of endocrine-disrupting chemicals in wildlife and humans. Environ. health. perspect., 101, 378-384.

[2] Brooking J, Davis SS and Illum L.(2001). Transport of nanoparticles across the rat nasal mucosa. J. Drug Target., 9, 267-279.

[3] Wang J, Liu Y, Jiao F, Lao F, Li W, Gu Y, Li Y, Ge C, Zhou G, Li B and Zhao Y.(2008). Time-dependent translocation and potential impairment on central nervous system by intranasally instilled TiO 2 nanoparticles. Toxicology, $254,82-90$.

[4] Wanrooij S and Falkenberg M.(2010). The human mitochondrial replication fork in health and disease. Bioch. Bioph. Acta., 1797, 1378-88.

[5] Singhal N, Gupta BS, Saigal R, Makkar J and Mathur R.(2000). Mitochondrial diseases: an overview of genetics, pathogenesis, clinical features and an approach to treatment. J. Postgrad Med, 46, 224-30. 
[6] Spikings EC, Alderson J and John JCS.(2006). Transmission of mitochondrial DNA following assisted reproduction and nuclear transfer. Hum Reprod, 12, 401-15.

[7] Parton LE, Ye CP, Coppari R, Enriori PJ, Choi B, Zhang CY, Xu C, Vianna CR, Balthasar N, Lee CE, Elmquist JK, Cowley MA and Lowell BB.(2007). Glucose sensing by POMCneurons regulates glucose homeostasis and is impaired in obesity. Nature, 449, 228-32.

[8] Reyes A, Mezzina M and Gadaleta G.(2002). Human mitochondrial transcription factor A (mtTFA): gene structure and characterization of related pseudogenes. Gene, 291, 223-32.

[9] Dong X., Ghoshal K, Majumder S. Yadav SP and Jacob ST.(2002). Mitochondrial transcription factor A and its downstream targets are up-regulated in a rat hepatoma. J. Biol. Chem, 277, 43309-43318.

[10] Chandrika C, Scott M, Bayne AV, Peter S, Jingyan T, Nadja C, Croteau DL and Bohr VA.(2010). The mitochondrial transcriptions factor A functions in mitochondrial base excision repair. DNA Repair, 9, 1080-1089.

[11] Thundathil J, Filion F and Smith LC.(2005).Molecular control of mitochondrial function in preimplantation mouse embryos. Mol. Reprod. Dev, 71, 405-413.

[12] Li N, Stojanovski S and Maechler P.(2012). Mitochondrial Hormesis in Pancreatic $\beta$ Cells: Does Uncoupling Protein 2 Play a Role. A review. Oxid. Med. Cell. Long.

[13] Aquila H, Link TA and Klingenberg M.(1985). The uncoupling protein from brown fat mitochondria is related to the mitochondrial ADP/ATP carrier. Analysis of sequence homologies and of folding of the protein in the membrane. EMBO J, 4, 2369-76.

[14] Liu J, Li J, Li W and Wang C.(2013). The Role of Uncoupling Proteins in Diabetes Mellitus. A Rev. J. Diab.

[15] Ledesma A, Lacoba MG and Rial E.(2002). The mitochondrial uncoupling proteins. Genobiol, 3, 3015.1-3015.9.

[16] Fleury C, Neverova M, Collins S, Raimbault S, Champigny O, Levi-Meyrueis C, Bouillaud F, Seldin MF, Surwit RS, Ricquier D and Warden CH.(1997). Uncoupling protein-2: a novel gene linked to obesity and hyperinsulinemia. Nat. Genet, 15, 269-72.

[17] Souza BM, Assmann TS, Kliemann LM, Gross JL, Canani LH and Crispim D.(2011). The role of uncoupling protein 2 (UCP2) on the development of type 2 diabetes mellitus and its chronic complications. Arg Bras Endocrinol. Metabol, 55, 239-248.

[18] Nedergaard J and Cannon B.(2003). The 'novel' 'uncoupling' proteins UCP2 and UCP3: what do they really do? Pros and cons for suggested functions. Exp. Physiol, 88, 65-84.

[19] Szalay B, Tátrai E, Nyírő G, Vezér T and Dura G.(2011). Potential toxic effects of iron oxide nanoparticles in vivo and in vitro experiments.J. Appl. Toxicol, 32, 446-453.

[20] Sharma VK, Yngard RA and Lin Y.(2009). Silver nanoparticles: green synthesis and their antimicrobial activities. Adv. Colloid Interface Sci, 145, 83-96.

[21] AOAC.(1990). Official Methods of Analysis of the Association of Official Analytical Agricultural Chemists, 13 th ed. Benjamin, Franklin Station, Washington, DC, 587.

[22] Piantadosi CA and Suliman HB.(2006). Mitochondrial transcription factor A induction by redox activation of nuclear respiratory factor 1 . J. Biol. Chem, 281, 324-333.

[23] Duncan DB.(1955). Multiple Range and Multiple (F-test). Biomaterials, 11, 1-42.

[24] Teodoro JS, Rolo AP and Palmeira CM.(2013). The NAD ratio redoxparadox: why does too much reductive power cause oxidativestress? Toxicol. Mech. Methods, 23, 297-302.

[25] Wallace DC. (2011). Bioenergetic origins of complexity and disease. Cold Spring Harb. Symp. Quant. Biol, 76, 116.

[26] Ruiz-Pesini E, Diez C, Lapena C, Perez-Martos A, Montoya J, Alvarez E, Arenas J and Lo' pez-Pe'rez MJ.(1998). Correlation of sperm motility with mitochondrial enzymatic activities. Clin. Chem, 44, 1616-1620.

[27] Nakada K, Sato A, Yoshida K, Morita T, Tanaka H, Inoue S, Yonekawa H and Hayashi J.(2006). Mitochondriarelated male infertility. Proc. Natl. Acad. Sci. U S A, 103, 15148-15153.

[28] Malarkey CS, Bestwick M, Kuhlwilm JE, Shadel GS and Churchill ME.(2012). Transcriptional activation by mitochondrial transcription factor A involves preferential distortion of promoter DNA. Nucleic acids Res, 40, 614624. 
[29] Teodoro JS, Simões AM, Duarte FV, Rolo AP, Murdoch RC, Hussain SM and Palmeira CM.(2011). Assessment ofthe toxicity of silver nanoparticles in vitro: a mitochondrialperspective. Toxicol. In Vitro, 25, 664-670.

[30] Rodrigues AS, Lacerda B, Moreno AJ and Ramalho-Santos J.(2010). Proton leak modulation in testicular mitochondria affects reactive oxygen species production and lipid peroxidation. Cell Biochem. Funct, 28, 224231.

\section{How to cite this article}

Younus AI, Yousef MI, Kamel MA, Younus MIand Abdulrahman JM. (2020). Reproductive toxicity of iron oxide nanoparticles, silver nanoparticles and their mixture in male rats: Effects on testicular gene expression. World Journal of Advanced Research and Reviews, 7(2), 75-81. 